\title{
Economical and technical aspects of using air heat pumps for hot water
}

\author{
Mariusz, Szreder ${ }^{1, *}$ \\ ${ }^{1}$ Warsaw University of Technology, Faculty of Civil Engineering, Mechanics and Petrochemistry, \\ Łukasiewicza 17, 09-400 Płock, Poland
}

\begin{abstract}
The paper presents selected technical and economic aspects related to the use of air heat pumps for the preparation of domestic hot water DHW. The research shows that heating the water in the $130 \mathrm{dm}^{3}$ storage tank with the A21/W30-50 profile lasted an average of 130 minutes, and the heat pump consumed about $2.2 \mathrm{kWh}$ of energy per one heating cycle. Heating water in a $130 \mathrm{dm}^{3}$ storage tank from $25^{\circ} \mathrm{C}$ to $40^{\circ} \mathrm{C}$ lasted an average of 60 minutes, while heating water for another $5^{\circ} \mathrm{C}$ took 30 minutes. The operation of the heat pump in the higher temperature of the water in the storage tank is less effective, making the heating of water in the tank above $50^{\circ} \mathrm{C}$ is ineffective.
\end{abstract}

\section{Introduction}

The dominant trend in utility water heating installations is the continuous reduction of energy demand and increasing the use of free renewable energy. The whole fits in with the European Union strategy regarding the reduction of $\mathrm{CO}_{2}$ emissions and the development of Renewable Energy Sources [1].

In recent years, heat pumps have become a relatively popular solution used to heat domestic hot water. This is mainly due to the low purchase price and the simplicity of assembly of this system. Compared to solar systems, their advantage is lower investment price and hot water production practically throughout the year [2].

Solar collectors and air heat pumps are especially recommended as an alternative to electric heating, fuel oil or liquid gas. The main argument is lower operating costs. Undoubtedly, such association is also a viable alternative in the absence of a natural gas connection. Supplementing the installation with a solid fuel boiler with an air heat pump and solar collectors is very beneficial due to the cumbersome and economically and ecologically unjustified exploitation of the boiler outside the heating season [5].

The integration of many systems is becoming more and more popular [3,4]. The use of a heating system integrated with an air heat pump and solar collectors requires proper adaptation of the installation as well as an economic justification for the investment. The main justification for associating the solar collector system and the heat pump are the rising prices of traditional fuels or the lack of availability of cheaper heat energy carriers [6].

\footnotetext{
* Corresponding author: mariusz.szreder@pw.edu.pl
} 
To sum up, the integration of solar collectors with a heat pump will be more expensive to invest at each of them separately, but in this way we get the cheapest and most stable heating system for hot water outside the heating season.

\section{Construction of the air heat pump for domestic hot water}

There are various technical solutions available on the market, intended exclusively for DHW heating, including an integral water tank in fig. 1 or intended for cooperation with an existing heating system in a building. A modular variant of the heat pump (without a tank) enables easy installation of the heat pump in a boiler room, in which there is e.g. a solid fuel boiler and a water tank, which does not need to be replaced with a new one.

In the first solution, it is possible to obtain higher coefficient of performance COP values due to the direct integration of the condenser with the hot water tank $[8,9]$.

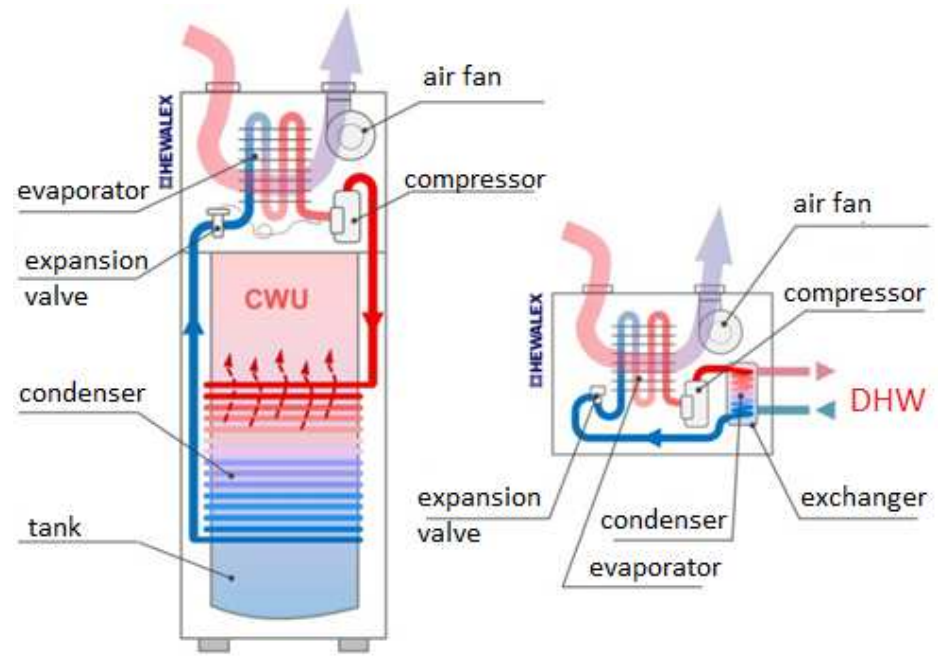

Fig. 1. Construction of air heat pump for DHW [9]

The heat pump fan sucks warm air from the room and pushes it through the evaporator, on which the air is cooled by approx. $5 \div 7 \mathrm{~K}$, and then it is removed outside the building or into the same room. Due to this small cooling of the air, the heat pump receives a large amount of heat from it, which is used to heat domestic hot water in the tank. In the summer, warm air is sucked in from outside the building, and the air cooled down in the evaporator can be directed to the inside of the building [11].

\section{Research stand}

The Hewalex DHW heat pump in the version with an external hot water tank was used for the preparation of research stand. This solution enables the use of storage tank with different water capacity, the method of installing a $2.5 \mathrm{~kW}$ DHW heat pump in the research stand is shown in Fig. 2.

Characteristic for this heat pump is to connect the upper source to the circulation circuit in the tank, not to the built-in coil. In the designed research stand, two tanks with a capacity of $130 \mathrm{dm}^{3}$ were used. This solution enables testing of a heat pump with variable heat load of the upper heat source. 
The designed research stand has been equipped with the EKONTROL system offered by Hewalex. The measuring equipment enables the heat flow to be measured in the heat pump's upper source circuit. The research stand has been equipped with an additional G922-COP measuring module for testing the COP coefficient with access to the database at ekontrol.pl.

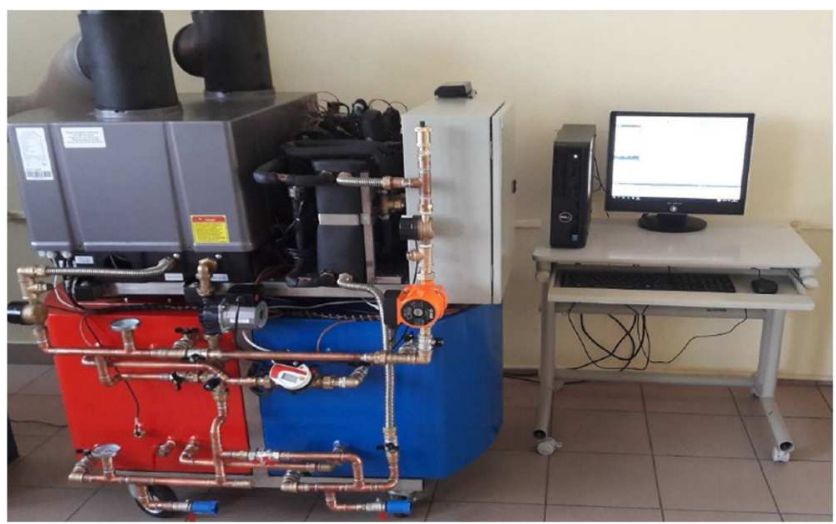

Fig. 2. Installation of a DHW heat pump in a research stand

\section{Experimental results}

The ventilation air of the laboratory room and outside air were used for the tests. The series of measurements was carried out for cases of heating water in storage tanks of 130 and $260 \mathrm{dm}^{3}$ from room temperature to a water temperature of $50^{\circ} \mathrm{C}$. The measurements were carried out for 3 speeds of a standard $60 \mathrm{~W}$ circulation pump, yielding the average water flow rate, respectively $0.17 \mathrm{~kg} \mathrm{~s}^{-1}$ on $1^{\text {st }}$ gear, $0.24 \mathrm{~kg} \mathrm{~s}^{-1}$ on $2^{\text {nd }}$ gear and $0.27 \mathrm{~kg} \mathrm{~s}^{-1}$ on $3^{\text {rd }}$ gear.

Fig. 3 shows changes in registered temperatures in the heat pump cycle for the use of outdoor air at $7{ }^{\circ} \mathrm{C}$ for heating water in a $260 \mathrm{dm}^{3}$ storage tank to $50^{\circ} \mathrm{C}$ (A7/W30-50 profile) and setting the circulation pump to $3^{\text {rd }}$ gear.

The increase in the temperature of the water in the storage tank gradually forced an increase in the temperature of water in the heating circuit, so that the temperature of condensation also gradually increased. As the temperature in the heating circuit increased, the thermal load of the heat pump has been gradually reduced, which is evidenced by the recorded increase in the evaporating temperature of the refrigerant at a constant air temperature at the inlet to the evaporator [10].

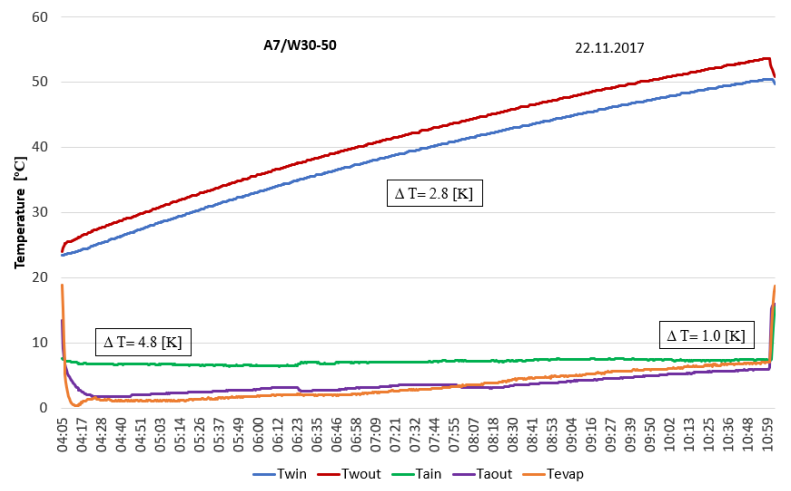

Fig. 3. Graph of temperature changes in the heat pump for outside air circulation of $7{ }^{\circ} \mathrm{C}$ and water mass flow $0,27 \mathrm{~kg} \mathrm{~s}^{-1}$ for a storage tank of $260 \mathrm{dm}^{3}$ 
On average, 20 minutes after the heat pump was switched on, the heat pump's operating conditions stabilized. In this case, the evaporating temperature of the refrigerant was $1.1^{\circ} \mathrm{C}$ at the beginning of the heating cycle and gradually increased to $7^{\circ} \mathrm{C}$ at the end of the heating cycle.

Temperature difference at the inlet and outlet of the water in the heating circuit for the water mass flow $0.27 \mathrm{~kg} \mathrm{~s}^{-1}$ amounted to $\Delta \mathrm{T}_{\mathrm{w}}=2.8 \mathrm{~K}$ on average, while in the evaporator circuit it has changed from $\Delta \mathrm{T}_{\mathrm{a}}=4.8^{\circ} \mathrm{K}$ to $\Delta \mathrm{T}_{\mathrm{a}}=1 \mathrm{~K}$.

For the A7/W30-50 power supply profile, the heat pump produced $21.7 \mathrm{kWh}$ of heat energy, consuming $5.8 \mathrm{kWh}$ of electricity, and the average COP was 3.75 . The registered measurement results show that the evaporating temperature of the refrigerant for stabilized operating conditions is close to the temperature of the air at the outlet from the evaporator.

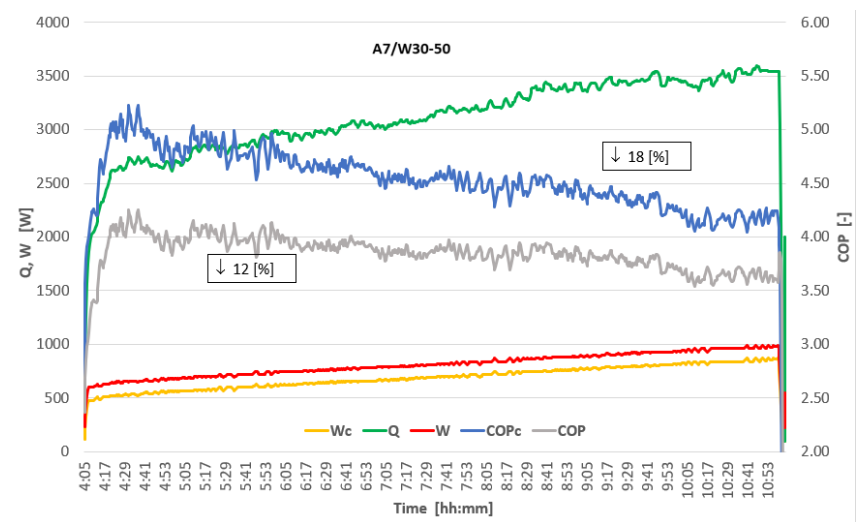

Fig. 4. Diagram of changes in the demand for electric power and registered heating power in the heat pump for the external air circulation of $7{ }^{\circ} \mathrm{C}$ and water flow rate of $0.24 \mathrm{~kg} \mathrm{~s}^{-1}$

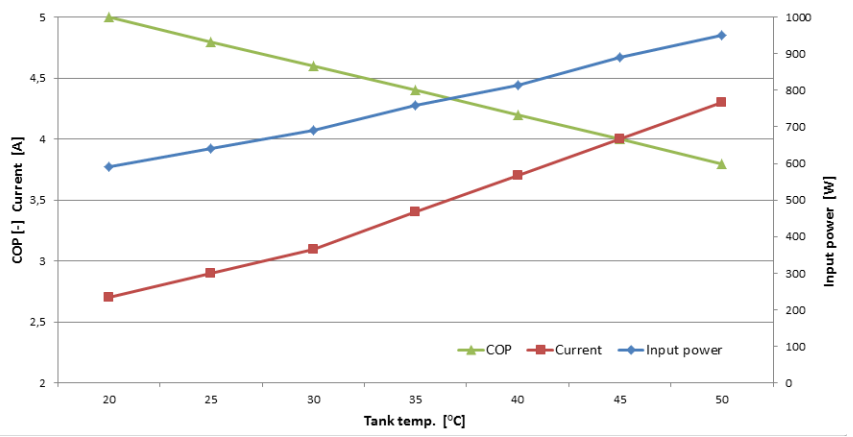

Fig. 5. List of recorded current values, electrical power consumption and COP for ventilation air $21^{\circ} \mathrm{C}$

Momentary COP and heating power values were determined for each measuring cycle. Fig. 4 presents data registered in the G922-COP module. The demand of a rotary compressor for electric power varied in the range of $510 \div 860 \mathrm{~W}$ depending on the condensing temperature. In fixed conditions, the heat pump operated at a maximum heating power of $3520 \mathrm{~W}$. As a result, COP values for the compressor were obtained in the range from 5.10 to 4.25 for stable conditions of the heat pump, calculated COP for the A7/W30-50 profile was 4.55. The demand of the circulating pump and heat pump control system for electric power was $120 \mathrm{~W}$. Thus, the heat pump's COP for the A7/W30-50 profile dropped to 3.80 (a decrease by 16\%) [7].

Fig. 5 shows how the demand for electric power and COP of the heat pump changes depending on the temperature of the water in the tank. The results of the measurements show 
that the air heat pump achieved the highest $\mathrm{COP}=5.00$ in the first phase of heating the water in the tank. The current consumption by the compressor was below $3 \mathrm{~A}$, and the demand for electrical power was $600 \mathrm{~W}$. In the final phase of heating, the efficiency of the heat pump fell to $\mathrm{COP}=3.60$, and the demand for electrical power increased to $950 \mathrm{~W}$.

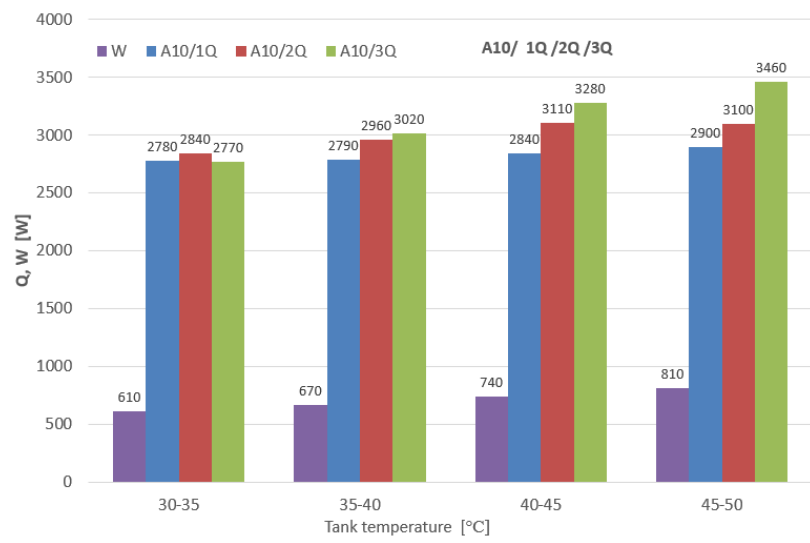

Fig. 6. Comparison of the average values of heating powers for selected water temperature ranges in the tank

At full heat load, the heat pump achieves maximum efficiency in the range of higher water temperatures in the heating circuit (increase by $25 \%$ ). The air heat pump obtained for the $\mathrm{A} 21 / \mathrm{W} 30-50$ profile the highest $\mathrm{COP}=4.55$ in the first phase of water heating in the storage tank for the water mass flow $0.27 \mathrm{~kg} \mathrm{~s}^{-1}$, and the demand for electrical power was $610 \mathrm{~W}$. In the final heating phase, efficiency of the heat pump dropped to the value of $\mathrm{COP}=3.95$, and the demand for electric power increased to $810 \mathrm{~W}$. The values averaged for the whole measurement cycle were: heating power generated at $3440 \mathrm{~W}$, with the demand for $840 \mathrm{~W}$ of electric power, one obtained $\mathrm{COP}=4.10$.

\section{Conclusion}

During the laboratory tests, the measurement data were recorded on an ongoing basis in the EKONTROL system database. In the heat pump control system, the compressor start-up block is automatically activated if the temperature of the air supplying the lower source falls below $0{ }^{\circ} \mathrm{C}$, due to the low efficiency of the device. This means that for negative ambient temperatures, the pump's operation with the use of outside air is ineffective. Pump operation in winter is possible with the use of ventilation air, but with the discharge of cooled air outside the building.

The research shows that heating the water in the $130 \mathrm{dm}^{3}$ storage tank with the A21/W3050 profile lasted an average of 130 minutes, and the heat pump consumed about $2.2 \mathrm{kWh}$ of energy per one heating cycle. Heating water in a $130 \mathrm{dm}^{3}$ storage tank from $25^{\circ} \mathrm{C}$ to $40^{\circ} \mathrm{C}$ lasted an average of 60 minutes, while heating water for another $5{ }^{\circ} \mathrm{C}$ took 30 minutes. The operation of the heat pump in the higher temperature of the water in the storage tank is less effective, making the heating of water in the tank above $50^{\circ} \mathrm{C}$ is uneconomical.

With $1 \mathrm{kWh}$ of electric energy collected by the compressor, the presented heat pump is able to generate $3.6 \mathrm{kWh}$ of heat energy in 75 minutes for the water mass flow of $0,17 \mathrm{~kg} \mathrm{~s}^{-1}$. For the water mass flow of $0,27 \mathrm{~kg} \mathrm{~s}^{-1}$, from $1 \mathrm{kWh}$ one may generate $4,5 \mathrm{kWh}$ of heat energy in 68 minutes.

Domestic hot water heat pumps may replace the use of solar collectors, however, it is important to remember both their advantages and limitations. The lowest operating costs are 
characteristic for a solar installation, which is also a less complex device, with proven reliability and durability. Heat pumps are also covered by shorter warranty periods, which, depending on the manufacturer, range from 2 to 5 years (for solar collectors it is usually 10 years).

An air heat pump for DHW is an ideal solution for heating systems equipped with solid fuel boilers. It is a maintenance-free and economical system for producing domestic hot water outside the heating season.

\section{References}

1. Anifantis A.S., Performance assessment of photovoltaic, ground source heat pump and hydrogen heat generator in a stand-alone system for greenhouse heating, Chemical Engineering Transactions, 58, pp. 511-516, (2017)

2. Dong X, Tian Q, Li Z., Experimental investigation on heating performance of solar integrated air source heat pump. Applied Thermal Engineering, 123, pp. 1013-1020, (2017)

3. Guo J., Wu J., Wang R., Li S., Experimental research and operation optimization of an air-source heat pump water heater, Applied Energy, 88, pp. 4128-4138, (2011)

4. Jiang M., Wu J., Wang R., Research on the control laws of the electronic expansion valve for an air source heat pump water heater, Building and Environment, 46, pp. 19541961, (2011)

5. Jung H., Kang H., Yoon W., Performance comparison between a single-stage and a cascade multi-functional heat pump for both air heating and hot water supply, Journal of Refrigeration, 36, pp. 1431-1441, (2013)

6. Lachman P., Heat pumps in hybrid systems, InstalReporter, 4, pp. 27-30, (2014)

7. Miara M., Efficiency of heat pumps in real conditions of use, InstalReporter, 2, pp. 1216, (2011)

8. Peng J., Li H., Zhang C., Performance comparison of air-source heat pump water heater with different expansion devices. Applied Thermal Engineering, 99, pp. 1190-1200, (2016)

9. Piwowarczyk Sz., Air heat pump for hot water, InstalReporter, 9, pp. 40-46, (2014)

10. Szreder M., Investigations into the influence of functional parameters of a heat pump on its thermal efficiency, TEKA Commission of Motorization and Energetics in Agricultures, 13, pp. 191-196, (2013)

11. Szreder M., A field study of the performance of a heat pump installed in a low energy house, Applied Thermal Engineering, 71, pp. 596-606, (2014) 